\title{
MG-132 reverses multidrug resistance by activating the JNK signaling pathway in $\mathrm{FaDu} / \mathrm{T}$ cells
}

\author{
JUKE MA ${ }^{1,2^{*}}$, ZHENGHUA LV ${ }^{1,2^{*}}$, XIUXIU LIU ${ }^{1,2}$, XIANFANG LIU ${ }^{1,2}$ and WEI XU ${ }^{1,2}$ \\ ${ }^{1}$ Department of Otorhinolaryngology Head and Neck Surgery, Shandong Provincial Hospital Affiliated to Shandong University, \\ Jinan, Shandong 250021; ${ }^{2}$ Shandong Institute of Otolaryngology Affiliated to Shandong Province, \\ Jinan, Shandong 250022, P.R. China
}

Received November 3, 2017; Accepted May 23, 2018

DOI: $10.3892 / \mathrm{mmr} .2018 .9138$

\begin{abstract}
Multidrug resistance (MDR) is a major impediment to cancer therapy. MG-132 has been identified to be effective against MDR in several types of cancer. However, the mechanism of MG-132 in head and neck squamous cell carcinomas remains unknown. Based on our previous study, the present detected $P$-gp and P-gp expression in hypopharyngeal carcinoma FaDu cells, revealing that their expression was lower than that observed in the MDR cell line $\mathrm{FaDu} / \mathrm{T}$. To reverse the MDR of FaDu/T cells, the present study introduced MG-132 and demonstrated that the high expression of $P-g p / \mathrm{P}-\mathrm{gp}$ in $\mathrm{FaDu} / \mathrm{T}$ cells was attenuated in a time-dependent manner. MG-132 also strengthened the sensitivity of FaDu/T cells to multidrugs. c-Jun N-terminal kinase (JNK) activation was further observed in $\mathrm{FaDu} / \mathrm{T}$ cells. However, $P$ - $g p / \mathrm{P}$-gp did not decrease when FaDu/T cells were pretreated with SP600125. These results indicated that MG-132 reversed the MDR of hypopharyngeal carcinoma by downregulating $P-g p / \mathrm{P}-\mathrm{gp}$, and the underlying mechanism may be associated with the activation the of the JNK signaling pathway.
\end{abstract}

\section{Introduction}

A significant obstacle in the clinical treatment of cancer patients is multidrug resistance (MDR) (1). Many genes are reportedly related with MDR. Among them, the most significant are ATP-binding cassette (ABC) genes (2). Humans have $49 \mathrm{ABC}$ genes, and the high expression of these genes in cancer patients results in decreased intracellular accumulation of

Correspondence to: Dr Wei Xu, Department of Otorhinolaryngology Head and Neck Surgery, Shandong Provincial Hospital Affiliated to Shandong University, 324 Jingwu Road, Huaiyin, Jinan, Shandong 250021, P.R. China

E-mail: xuwhns@126.com

\section{${ }^{*}$ Contributed equally}

Key words: multidrug resistance, MG-132, P-glycoprotein, c-Jun $\mathrm{N}$-terminal kinase, c-Jun chemotherapy drugs in spite of their different chemical structures (3). As the first identified and typical ABC transporter, $P$-gp/P-gp has the MDR characteristic of effluxing a number of commonly used chemotherapeutic agents, e.g., Taxol, doxorubicin, vincristine, vinblastine, colchicine, actinomycin $\mathrm{D}$, and mitomycin C (4). Thus, the high expression of P-gp plays a critical role in many kinds of cancer-chemotherapy failure, and identifying approaches to overcoming P-gp-mediated drug resistance is urgent.

The development of MDR reversal has progressed for over 35 years (5). Classical chemosensitizers including verapamil, cyclosporine A, and PSC833 can reverse P-gp-mediated MDR, but their toxicity and other side effects in vivo limit their clinical application (6). To overcome their low efficiency and high toxicity in cancer treatment, the proteasome inhibitor MG132 has been found to be a potent P-gp-inhibitor $(7,8)$. To elucidate the molecular basis underlying the reversal of $P$ - $g p / \mathrm{P}-\mathrm{gp}$ by MG-132 in head and neck squamous cell carcinomas (HNSCCs), we conducted an experiment on the hypopharyngeal carcinoma cell line $\mathrm{FaDu}$ and the multidrug resistance (MDR) cell line $\mathrm{FaDu} / \mathrm{T}$ induced by Taxol that had been established in our previous study.

\section{Materials and methods}

Materials. The human hypopharyngeal carcinoma cell line FaDu and human bronchial epithelioid (HBE) cells were obtained from the American Type Culture Collection (Manassas, VA, USA). Media and serum were purchased from Gibco; Thermo Fisher Scientific, Inc.(Waltham, MA, USA). The primary antibodies anti-MDR1/P-gp, anti-actin, and anti-nuclear factor- $\kappa \mathrm{B}(\mathrm{NF}-\kappa \mathrm{B})$ were all purchased from Santa Cruz Biotechnology, Inc. (Santa Cruz, CA, USA). The primary antibodies anti-p-c-Jun N-terminal kinase (JNK) and anti-p-c-Jun were from Cell Signaling Technology. All other reagents were from Sigma-Aldrich; Merck KGaA (Darmstadt, Germany).

Cell culture and establishment of the resistant cell line $\mathrm{FaDu} / \mathrm{T}$. FaDu and HBE cells were cultured as a monolayer in Dulbecco's modified Eagle's medium containing 10\% fetal calf serum, $100 \mathrm{U} / \mathrm{ml}$ penicillin, and $100 \mathrm{mg}$ streptomycin at $37^{\circ} \mathrm{C}$ in humidified atmosphere composed of $95 \%$ air and $5 \% \mathrm{CO}_{2}$. 
The methods of establishing the resistant cell line $(\mathrm{FaDu} / \mathrm{T})$ has been described previously (9).

Cytotoxicity test. Cell viability was detected with cell counting kit-8 (CCK-8) assay kits. HBE cells were seeded in 24-well culture plates. The plates were placed in an incubator for $24 \mathrm{~h}$, and the culture medium was changed to collect MG-132.CCK-8 assays were performed $48 \mathrm{~h}$ after treatment with different concentrations of MG-132. At the time of the CCK- 8 assay, we added $10 \mu \mathrm{l}$ of CCK- 8 solution to each well of the plate, which was incubated for $2 \mathrm{~h}$ at $37^{\circ} \mathrm{C}$. Absorbance was measured at $450 \mathrm{~nm}$ using a microplate reader (BioTek, Winooski, VT, USA). Results were used to measure cell growth.

Reverse transcription (RT)- and semi-quantitative polymerase chain reaction ( $s q P C R$ ). Total RNA was extracted using TRIzol (Invitrogen; Thermo Fisher Scientific, Inc). RT-PCR was performed using the ExScript RT reagent kit (Takara, Dalian, China) in a final volume of $20 \mu \mathrm{l}$ containing $1 \mu \mathrm{g}$ of total RNA, $4 \mu \mathrm{l}$ of $5 \mathrm{X}$ ExScript buffer, $1 \mu \mathrm{l}$ of dNTP mixture, $1 \mu \mathrm{l}$ of oligo(dT) primer, $0.5 \mu \mathrm{l}$ of ExScript RTase, $0.5 \mu \mathrm{l}$ of RNase inhibitor, and RNase-free water to a volume of $20 \mu \mathrm{l}$. This reaction was performed at $42^{\circ} \mathrm{C}$ for $15 \mathrm{~min}$ and terminated by heating at $95^{\circ} \mathrm{C}$ for $2 \mathrm{~min}$. PCR was performed following the manufacturer's instructions of Takara Taq ${ }^{\mathrm{TM}}$ under the following conditions: Pre-degeneration at $95^{\circ} \mathrm{C}$ for $3 \mathrm{~min}$, degeneration at $95^{\circ} \mathrm{C}$ for $60 \mathrm{sec}$, renaturation at $58^{\circ} \mathrm{C}$ for $45 \mathrm{sec}$, and elongation at $72^{\circ} \mathrm{C}$ for $60 \mathrm{sec}$, for a total of 25 cycles. sqPCR was performed by running the products on a $1 \%$ agarose gel, and the bands were quantified using ImageJ v1.48 (National Institutes of Health, Bethesda, MD, USA). All experiments were conducted thrice. The P-gp primers were as follows: Forward, 5'-CTGCTCAAGTTAAAGGGGCTAT-3' and reverse, 5'-AAC GGTTCGGAAGTTTTCTATT-3'. The actin primers were as follows: Forward, 5'-GTGGGGCGCCCCAGGCACCA-3' and reverse, 5'-CTCCTTAATGTCACGCACGATTT-3'.

Western blot analysis. Total protein was extracted using radioimmune precipitation assay buffer (Sigma-Aldrich; Merck KGaA) and protein lysis buffer following the manufacturer's protocols. Nuclear proteins were solubilized and fractionated by sodium dodecyl sulfate-polyacrylamide gel electrophoresis.

The Bradford method was used to determine the protein concentration of the supernatant. Samples $(40 \mu \mathrm{g}$ of total protein each) were used in western blot analysis with the first antibodies $(P-g p / \mathrm{P}-g \mathrm{p} 1: 400$, mouse antihuman; actin, 1:2,000, mouse antihuman; P-JNK 1:1,000, rabbit antihuman; and p-c-Jun 1:200, goat antihuman). The bands of $P-g p / \mathrm{P}-\mathrm{gp}$, P-JNK, p-c-Jun, and actin were visualized at apparent molecular weights of 170, 46/54, 39 and $43 \mathrm{kDa}$, respectively. Relative OD ratio was calculated with NIH software Image J by comparing to actin from three experiments.

Statistical analysis. Data are presented as the mean \pm standard error of the mean. Statistical calculations were performed using SPSS 16.0 software package (SPSS Inc., Chicago, IL, USA). One-way analysis of variance with a Bonferroni post hoc test were applied to analyze the variance, and $\mathrm{P}<0.05$ was considered to indicate a statistically significant difference.

\section{Results}

$m R N A$ and protein levels of $P$-gp/P-gp in FaDu and $\mathrm{FaDu} / \mathrm{T}$ cells. Compared with FaDu, P-gp (Fig. 1A) and P-gp (Fig. 1B) were upregulated in FaDu/T cells. ImageJ software was used to analyze the relative photodensity using actin as a loading control. Considering a value of 1 for FaDu groups, the relative photodensity of the $\mathrm{FaDu} / \mathrm{T}-200 \mathrm{nM}$ groups was as follows: $P$-gp/actin, $14.24 \pm 2.57$ and $12.42 \pm 2.23$; and P-gp/actin, 11.56 \pm 5.19 and $12.49 \pm 3.60$, respectively. Statistical analysis showed significant differences between FaDu and FaDu/T cells $(\mathrm{P}<0.05)$.

Downregulation of P-gp/P-gp by MG-132 in FaDu/T cells. To assess the capacity of MG132 in the downregulation of P-gp, $1.5 \mu \mathrm{M}$ MG-132 was applied in the present research. $P$-gp/P-gp expression in RNA (Fig. 2A) and protein (Fig. 2B) levels both decreased in a time-dependent manner. Considering a value of 1 for $\mathrm{FaDu} / \mathrm{T}(0 \mathrm{~h}) /$ actin, the relative photodensity of $P$-gp/actin in FaDu/T groups at 12, 24, 48 and $72 \mathrm{~h}$ was as follows: $0.41 \pm 0.05,0.17 \pm 0.06,0.11 \pm 0.01$ and $0.05 \pm 0.006$, respectively, Statistical analysis showed significant differences between different time-points $(\mathrm{F}=252.47 ; \mathrm{P}<0.05)$. Meanwhile, the relative photodensity of $\mathrm{P}$-gp/actin in $\mathrm{FaDu} / \mathrm{T}$ groups at 12 , 24,48 and $72 \mathrm{~h}$ was as follows: $0.73 \pm 0.12,0.65 \pm 0.15,0.42 \pm 0.05$ and $0.20 \pm 0.02$ respectively. Statistical analysis showed significant differences between different times $(\mathrm{F}=30.59$; $\mathrm{P}<0.05)$.

Status of JNK signaling pathway in drug-sensitive FaDu cells and in FaDu/T cells treated with $M G-132$. To examine the activation status of JNK signaling pathway in Taxol-sensitive $\mathrm{FaDu}$ cells, these cells were treated with Taxol for $48 \mathrm{~h}$, and then drug-sensitive $\mathrm{FaDu}$ cells were collected in a time-dependent manner. Western blot analysis showed that the JNK signaling pathway was activated in Taxol-sensitive FaDu cells. Furthermore, MG-132 functionally reversed the high expression of $\mathrm{P}-\mathrm{gp}$ and promoted the relative protein level of the JNK signaling pathway phosphorylation in a time-dependent manner when $\mathrm{FaDu} / \mathrm{T}$ cells were cultured in drug- and serum-free state for $24 \mathrm{~h}$ (Fig. 3).

SP600125, the inhibitor of the JNK signal pathway, inhibited the activation of this pathway. To ascertain the inhibitory effect of SP600125 on JNK signaling, we added MG-132 to $\mathrm{FaDu} / \mathrm{T}$ cells for $24 \mathrm{~h}$ after adding SP600125. As shown in Fig. 4, the expression of p-JNK and p-c-Jun did not significantly change.

SP600125 inhibited the MG-132-induced downregulation of $P-g p / P-g p$ in terms of RNA and protein levels. To ascertain the mechanism of MG-132 in downregulating P-gp, FaDu/T cells were pretreated with the JNK signal pathway inhibitor SP600125, followed by $1.5 \mu \mathrm{M} \mathrm{MG}-132$ for $72 \mathrm{~h}$. As shown in Fig. 5, in the absence of MG-132, FaDu/T cells with or without SP600125 pretreatment showed a similar expression of P-gp. By contrast, MG-132 treatment alone induced a significantly lower expression of P-gp, which can be reversed by pretreatment with SP600125. These results suggested that the JNK signaling pathway was involved in the MG-132-induced downregulation of $\mathrm{P}-\mathrm{gp}$ in $\mathrm{FaDu} / \mathrm{T}$ cells. Considering a value 
A

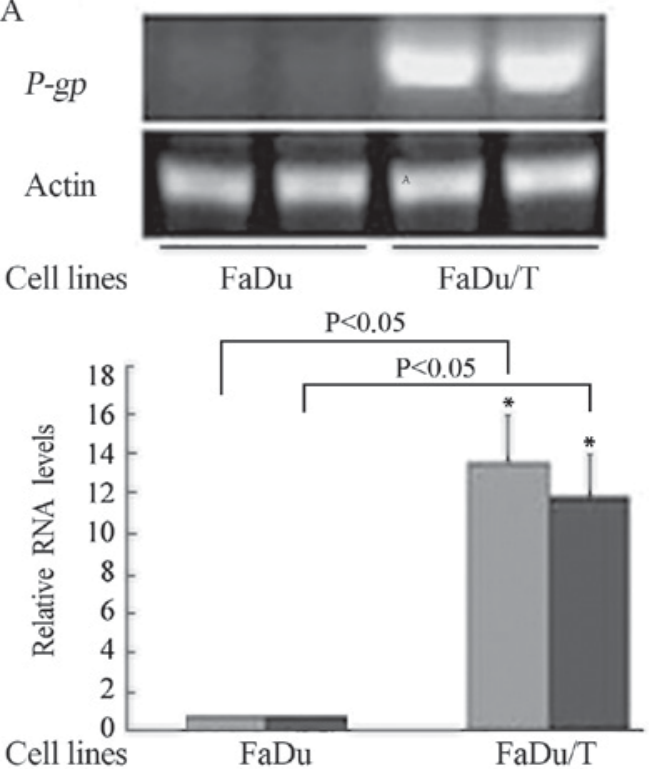

B

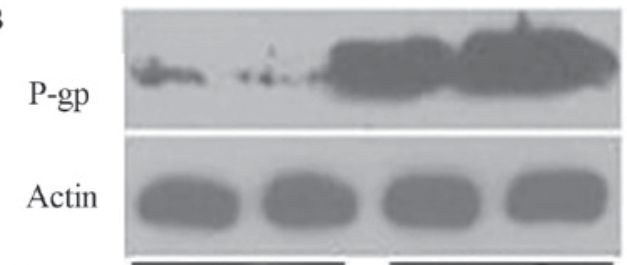

Cell lines

$\mathrm{FaDu}$

$\mathrm{FaDu} / \mathrm{T}$

$\mathrm{P}<0,05$

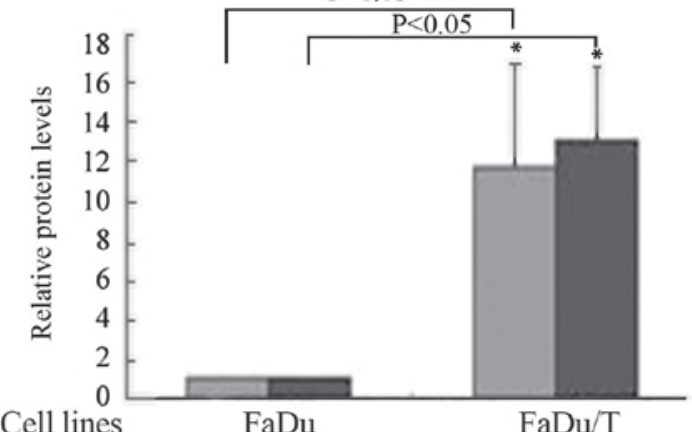

Figure 1. High P-gp expression in FaDu/T cell lines was detected at the mRNA and protein levels when compared with FaDu cells. (A) The multidrug resistance gene $P$ - $g p$ levels in $\mathrm{FaDu}$ and $\mathrm{FaDu} / \mathrm{T}$ cells were detected by reverse transcription-quantitative polymerase chain reaction analysis, and (B) the relative protein P-gp levels were detected by western blot analysis. Densitometry revealed that the gene and protein expression of $P$-gp/P-gp increased in FaDu/T cells. Graphs show the quantification of RNA and protein bands by densitometric scanning. The relative RNA and protein levels were presented as the ratio of densities of $P$-gp/P-gp to actin bands; bars within the same group represent repeated bands. Results are expressed as the mean \pm standard deviation. ${ }^{*}<0.05$, as indicated. P-gp, P-glycoprotein.

A
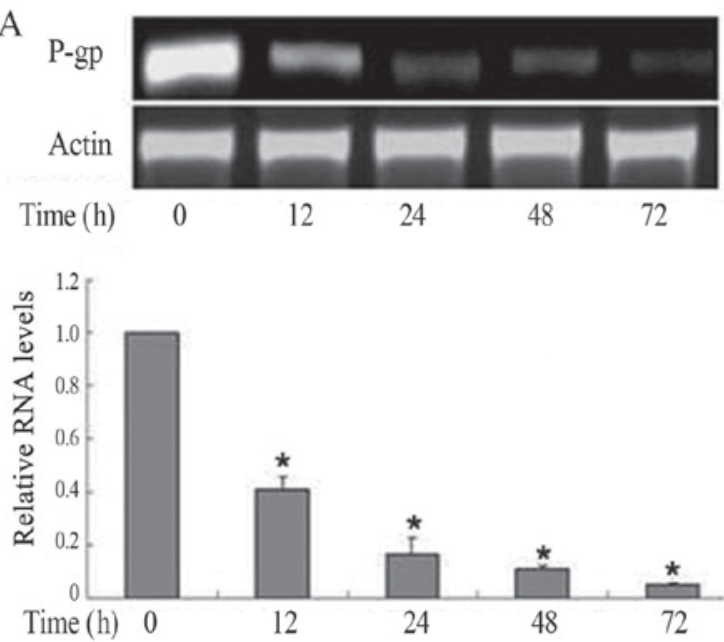

B
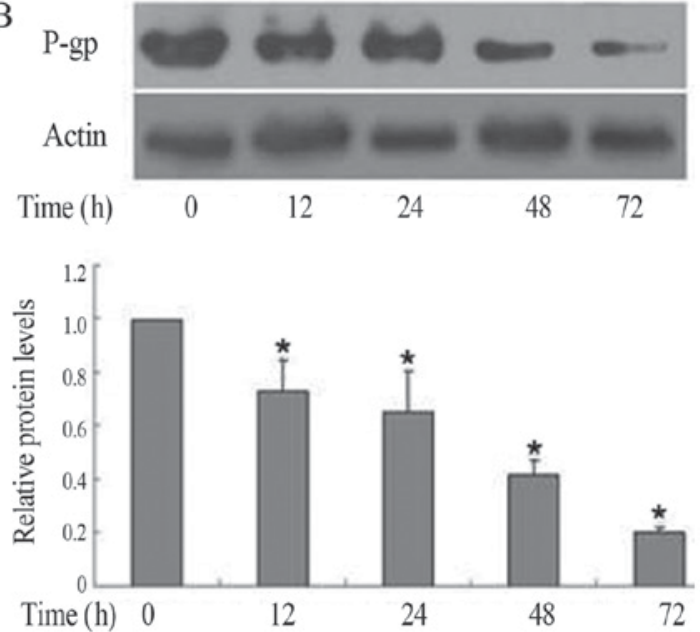

Figure 2. MG-132 downregulates the expression of P-gp at the mRNA and protein levels. The multidrug resistance (A) gene $P$ - $g p$ and (B) protein P-gp levels in FaDu/T cells were downregulated by MG-132 in a time-dependent manner. Quantification of RNA and protein bands by densitometric scanning is shown. The relative RNA and protein levels were presented as the ratio of densities of FaDu/T cells to actin bands. Results are expressed as the mean \pm standard deviation. ${ }^{*} \mathrm{P}<0.05$ vs. 0 h. P-gp, P-glycoprotein.

of 1 for FaDu/T/actin, the relative photodensity of $P$-gp/actin and $\mathrm{P}$-gp/actin in FaDu/T cells, FaDu/T cells treated with SP600125 and MG-132, and FaDu/T cells singly treated single with SP600125 groups was as follows: $24.23 \pm 2.97,24.65 \pm 3.77$, $23.88 \pm 2.35 ; 3.24 \pm 0.36,3.22 \pm 0.25$, and $3.12 \pm 0.25$, respectively. Statistical analysis showed a significant difference between different groups $(\mathrm{P}<0.05)$.

$M G-132$ inhibited the nuclear translocation of $N F-\kappa B$ in $\mathrm{FaDu} / \mathrm{T}$ cells. Compared with FaDu cells, the nuclear protein levels of $\mathrm{NF}-\kappa \mathrm{B}$ in $\mathrm{FaDu} / \mathrm{T}$ cells markedly increased when using lamin-A as a control. Considering a value of 1 for
$\mathrm{FaDu} / \mathrm{T}(0 \mathrm{~h}) /$ actin, the relative photodensity of FaDu/actin was $0.08 \pm 0.01$. Statistical analysis showed a significant difference between $\mathrm{FaDu}$ and $\mathrm{FaDu} / \mathrm{T}$ cells $(\mathrm{P}<0.05)$. However, the nuclear translocation of $\mathrm{NF}-\kappa \mathrm{B}$ was prohibited after short-time incubation of $\mathrm{FaDu} / \mathrm{T}$ cells with $\mathrm{MG}-132$. Considering a value of 1 for $\mathrm{FaDu} / \mathrm{T}(0 \mathrm{~h}) /$ actin, the relative photodensity of $\mathrm{FaDu} / \mathrm{T} / \mathrm{actin}(24$ and $48 \mathrm{~h}$ ) was $0.69 \pm 0.27$ and $0.16 \pm 0.01$, respectively (Fig. 6). Statistical analysis showed that the difference between different time-points was significant $(\mathrm{P}<0.05)$.

Cytotoxicity of MG-132 to HBE cells. To evaluate the clinical value of MG-132, HBE cells were treated with MG-132 in a 


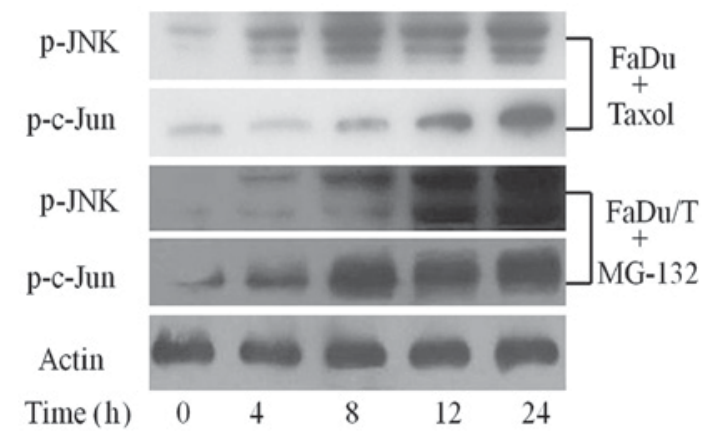

Figure 3. FaDu cells were treated with Taxol for $48 \mathrm{~h}$. Western blot analysis showed that the JNK signaling pathway was activated in Taxol-sensitive FaDu cells. MG-132 activated the JNK signaling pathways in a time-dependen manner in FaDu/T cells. P-JNK and p-c-Jun represented the activation condition of the JNK signaling pathway. With the introduction of MG-132 in $\mathrm{FaDu} / \mathrm{T}$ cells, the protein levels of p-JNK and p-c-Jun increased gradually. JNK, c-Jun N-terminal kinase; p-, phosphorylated.

concentration-dependent manner. Cell viability was detected with CCK-8 assay kits. As shown in Fig. 7, the viability of HBE cells were decreased significantly with increasing MG-132 concentrations. MG-132 exerted a cytotoxicity effect on HBE cells.

\section{Discussion}

To elucidate the molecular mechanism underlying the downregulation of membrane protein $P$ - $g p / \mathrm{P}-\mathrm{gp}$ by MG-132, we have previously established a multidrug-resistant cell line of FaDu to Taxol $(\mathrm{FaDu} / \mathrm{T})$ by stepwise exposure of normal FaDu cells to increased concentrations of Taxol for over 18 months. We find that $P$-gp/P-gp (P-glycoprotein) expression increases in $\mathrm{FaDu} / \mathrm{T}$ cell lines and that the MDR of $\mathrm{FaDu} / \mathrm{T}$ cells to DDP, 5-FU, Dox, and VCR is enhanced (9). However, when MG-132 was introduced into $\mathrm{FaDu} / \mathrm{T}$ cells, in addition to decreased P-gp, the MDR to DDP, 5-FU, and VCR also decreased. Based on the above investigation (10), we speculated that P-gp overexpression may be mainly responsible for MDR in FaDu/T cells Thus, the downregulation of P-gp by MG-132 was crucial to the reversal of MDR. Meanwhile, to clearly determine the mechanism of MG-132 in regulating P-gp in FaDu/T cells, we conducted further experiments.

As a proteasome inhibitor, MG-132 has anticancer effects through other cellular mechanisms, one of which is the activation of the JNK signal pathway (11). As a member of the MAPK family, the activation of the JNK signal pathway plays an important role in the growth, differentiation, and apoptosis of cancer cells (12). Several previous studies have suggested the existence of a negative binding site of AP-1 in the promoter region of the $P$ - $g p$ gene; thus, the activation of the JNK/c-Jun/AP-1 signal pathways can inhibit $P$ - $g p$ expression in human multidrug-resistant cells (13-15).

In the present study, with the application of MG-132 in FaDu or $\mathrm{FaDu} / \mathrm{T}$ cells cultured in a drug- and serum-free state, we found decreased $\mathrm{P}$-gp expression in $\mathrm{FaDu} / \mathrm{T}$ cells a time-dependent manner. We also detected that the JNK signaling pathway was effectively reactivated in a time-dependent manner. These findings, together with theoretical studies, led us to the hypothesis that decreased P-gp expression in FaDu/T cell lines caused

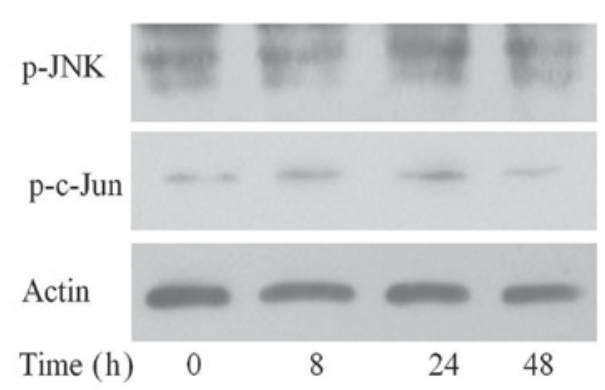

Figure 4. FaDu/T cells were pretreated with SP600125 for $24 \mathrm{~h}$ and then treated with MG-132. The protein levels of p-JNK and p-c-Jun did not markedly change. JNK, c-Jun N-terminal kinase; p-, phosphorylated.

by MG-132 was regulated by the JNK signal pathway. However, our data were insufficient to show how AP-1 was involved in $\mathrm{P}$-gp downregulation in $\mathrm{FaDu} / \mathrm{T}$ cell lines.

To further address this question, FaDu/T cells were pretreated with SP600125 (16), a small molecule inhibitor of the JNK signaling pathway for $24 \mathrm{~h}$. Results showed that the JNK signaling pathway was inactivated. Compared with $\mathrm{FaDu} / \mathrm{T}$ cells treated with only MG-132, P-gp expression was not significantly decreased. All of the above results indicated that P-gp downregulation was attributed to the activation of the JNK signal pathway.

MG-132 is a potent inhibitor in the degradation of I $\mathrm{B}$ proteins and thus, suppresses the nuclear translocation and activation of NF- $\kappa \mathrm{B}$. Given that the nuclear translocation of $\mathrm{NF}-\kappa \mathrm{B}$ was closely involved in P-gp expression $(17,18)$, we wondered whether this pathway also existed in hypopharyngeal cancer cells. Fig. 5 shows that compared with FaDu cells, the nuclear translocation of $\mathrm{NF}-\kappa \mathrm{B}$ in $\mathrm{FaDu} / \mathrm{T}$ cells increased, which was reversed when $\mathrm{FaDu} / \mathrm{T}$ cells was in the presence of MG-132 for 48 h. Meanwhile, the expression of P-gp significantly decreased, thereby providing evidence that MG132 downregulated P-gp expression also probably by suppressing $\mathrm{NF}-\kappa \mathrm{B}$ nuclear translocation. However, $\mathrm{FaDu} / \mathrm{T}$ cells were pretreated with SP600125, a small molecule inhibitor of the JNK signaling pathway for $24 \mathrm{~h}$. Compared with $\mathrm{FaDu} / \mathrm{T}$ cells treated with only MG-132, the expression of P-gp did not significantly decrease, although MG-132 can still suppress the activation of $\mathrm{NF}-\kappa \mathrm{B}$ under this condition. All of the above results indicated that $\mathrm{NF}-\kappa \mathrm{B}$ can upregulate $\mathrm{P}-\mathrm{gp}$ when $\mathrm{FaDu}$ cells were initially exposed to Taxol. However, in FaDu/T cell lines, the downregulation of P-gp was attributed to the activation of the JNK signal pathway, and the inactivation of $\mathrm{NF}-\kappa \mathrm{B}$ affected only the termination of P-gp expression. These lines of evidence suggested that the downregulation of P-gp in $\mathrm{FaDu} / \mathrm{T}$ cells was due to the activation of JNK signaling pathway. The interaction between the function of $N F-\kappa B$ and the JNK signaling pathway warrant further study.

In the present study, we presented evidence for the first time that MG-132 functionally downregulated P-gp expression by activating the JNK/c-Jun/AP-1 signal pathways, which promoted the negative regulation of AP-1 to P-gp. Therefore, the effects of MG-132 on P-gp downregulation may represent, at least in part, a novel strategy for overcoming the P-gp-related MDR of only FaDu cells to Taxol, and more cell lines of hypopharyngeal carcinoma to other chemotherapy agents such as DDP, 5-FU and Afatinib are needed to confirm the present findings in the future. 
A
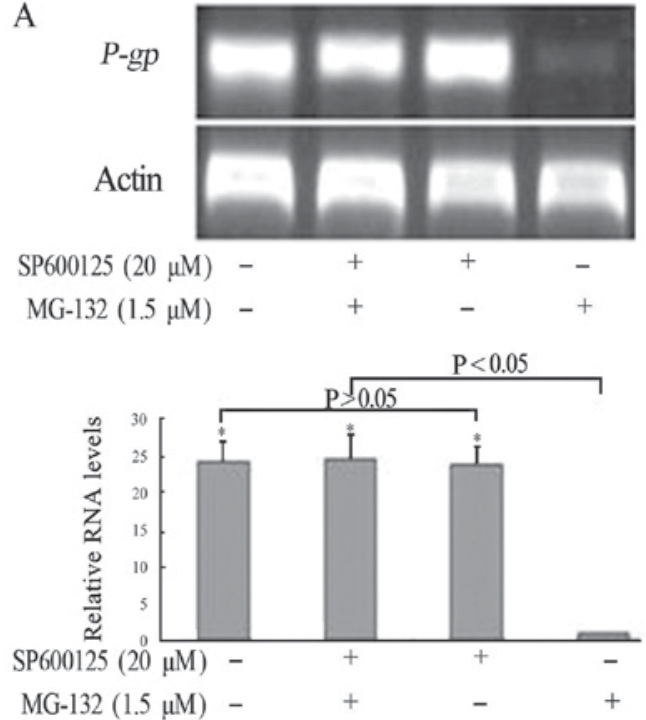

B

P-gp

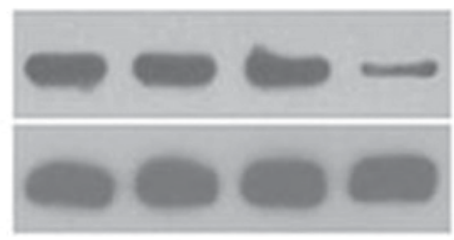

Actin

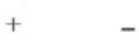

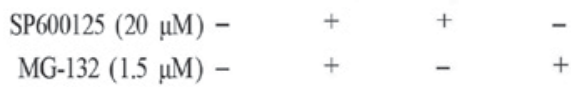

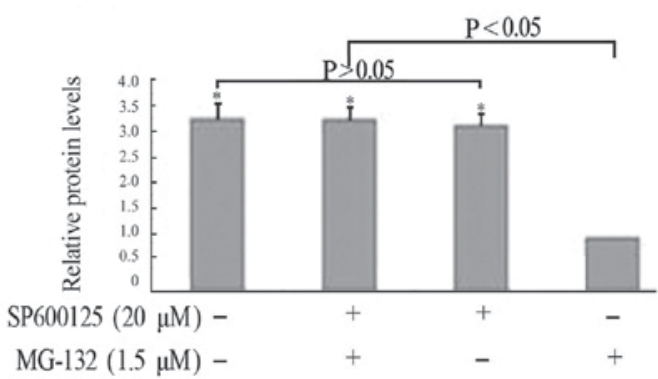

Figure 5. Effects of SP600125 on the MG-132-induced downregulation of P-gp expression at the gene and protein levels. The (A) mRNA and (B) protein levels of P-gp in FaDu/T cells pretreated with or without the JNK signal pathway inhibitor SP600125. In some groups, MG-132 was then introduced. FaDu/T cells underwent similar expression at the mRNA and protein levels $(\mathrm{P}>0.05)$. By contrast, MG-132 treatment alone induced a significantly low expression of $P$ - $g p$ and P-gp, which was reversed by pretreatment with SP600125. Graphs show the quantification of mRNA and protein bands by densitometric scanning. The relative mRNA and protein levels were presented as the ratio of densities of $P$ - $g p / \mathrm{P}$-gp to actin bands. Results are expressed as the mean \pm standard deviation. ${ }^{*} \mathrm{P}<0.05$, as indicated. P-gp, P-glycoprotein.
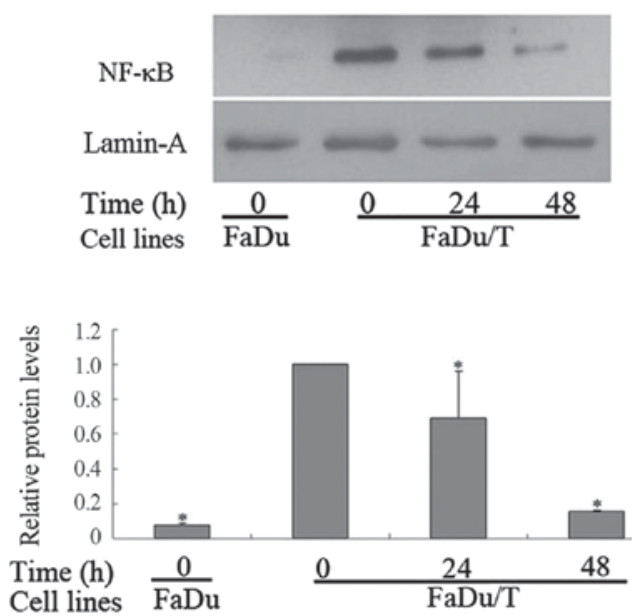

Figure 6. MG-132 inhibits the activation of NF- $\mathrm{kB}$ though nuclear translocation. Compared with the FaDu cell lines the, nuclear translocation of $\mathrm{NF}-\kappa \mathrm{B}$ in $\mathrm{FaDu} / \mathrm{T}$ cells increased. Conversely, the nuclear translocation of NF- $\mathrm{KB}$ was prohibited following the incubation of $\mathrm{FaDu} / \mathrm{T}$ cells with MG-132 for $48 \mathrm{~h}$. Graphs show the quantification of nuclear NF-kB bands by densitometric scanning. Considering a value of 1 for $\mathrm{FaDu} / \mathrm{T}(0 \mathrm{~h}) / \mathrm{lamin}-\mathrm{A}$, the relative photodensity of $\mathrm{FaDu} / \mathrm{T} / \mathrm{lamin}-\mathrm{A}$ ( 24 and $48 \mathrm{~h}$ ) was $0.69 \pm 0.27$ and $0.16 \pm 0.01$, respectively. Statistical analysis showed that the difference between different time-points was significant. " $\mathrm{P}<0.05$ vs. 0 h FaDu/T. $\mathrm{NF}-\kappa \mathrm{B}$, nuclear factor- $\kappa \mathrm{B}$.

\section{Acknowledgements}

Not applicable.

\section{Funding}

The present study was supported by the Shandong Provincial Outstanding Young Scientist Research Award Fund of China (grant no. BS2009YY013) and the Shandong Provincial

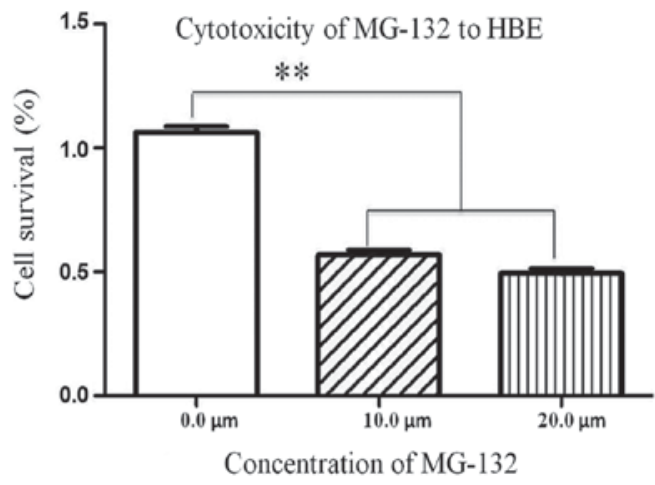

Figure 7. HBE cells were treated with MG-132 at various concentrations $(0,10$ and $20 \mu \mathrm{mol} / \mathrm{l})$ for $72 \mathrm{~h}$, and then cells were subjected to cell counting kit- 8 assay to measure cell viability. MG-132 induced HBE cell apoptosis in a concentration-dependent manner. ${ }^{* *} \mathrm{P}<0.01$, as indicated. HBE, human bronchial epithelioid.

International Science and Technology Cooperation Project of China (grant no. 2010GHZ20202).

\section{Availability of data and materials}

All data generated or analyzed during this study are included in this published article.

\section{Authors' contributions}

JM and ZL conceived and designed the research and drafted the manuscript. XxL and XfL acquired, analyzed and interpreted the data, and performed statistical analysis. WX conceived and designed the study, and revised the manuscript for important intellectual content. All authors read and approved the final manuscript. 


\section{Ethics approval and consent to participate}

Not applicable.

\section{Consent for publication}

Not applicable.

\section{Competing interests}

The authors declare that they have no competing interests.

\section{References}

1. Falasca $\mathrm{M}$ and Linton $\mathrm{KJ}$ : Investigational $\mathrm{ABC}$ transporter inhibitors. Expert Opin Investig Drugs 21: 657-666, 2012.

2. Rodrigues AC, Curi R, Genvigir FD, Hirata MH and Hirata RD The expression of efflux and uptake transporters are regulated by statins in Caco- 2 and HepG 2 cells. Acta Pharmacol Sin 30 : 956-964, 2009

3. Stavrovskaya AA and Stromskaya TP: Transport proteins of the ABC family and multidrug resistance of tumor cells. Biochemistry (Mosc) 73: 592-604, 2008.

4. Sharom FJ: The P-glycoprotein multidrug transporter. Essays Biochem 50: 161-178, 2011.

5. Amiri-Kordestani L, Basseville A, Kurdziel K, Fojo AT and Bates SE: Targeting MDR in breast and lung cancer: Discriminating its potential importance from the failure of drug resistance reversal studies. Drug Resist Updat 15: 50-61, 2012.

6. Ambudkar SV, Dey S, Hrycyna CA, Ramachandra M, Pastan I and Gottesman MM: Biochemical, cellular, and pharmacologica aspects of the multidrug transporter. Annu Rev Pharmacol Toxicol 39: 361-398, 1999.

7. Bang JH, Han ES, Lim I and Lee CS: Differential response of MG132 cytotoxicity against small cell lung cancer cells to changes in cellular GSH contents. Biochem Pharmacol 68: 659-666, 2004.

8. Qiu JH,Asai A, Chi S, Saito N,Hamada Hand Kirino T: Proteasome inhibitors induce cytochrome c-caspase-3-like protease-mediated apoptosis in cultured cortical neurons. J Neurosci 20: 259-265, 2000 .
9. Ma J, Lu S, Yu L, Tian J, Li J, Wang H and Xu W: FaDu cell characteristics induced by multidrug resistance. Oncol Rep 26: 1189-1195, 2011

10. Ma J, Yu L, Tian J, Mu Y, Lv Z, Zou J, Li J, Wang H and Xu W: MG132 reverse the malignant characteristics of hypopharyngeal cancer. Mol Med Rep 9: 2587-2591, 2014.

11. Park HS, Jun do Y, Han CR, Woo HJ and Kim YH: Proteasome inhibitor MG132-induced apoptosis via ER stress-mediated apoptotic pathway and its potentiation by protein tyrosine kinase $\mathrm{p} 561 \mathrm{ck}$ in human Jurkat T cells. Biochem Pharmacol 82: 1110-1125, 2011.

12. Huang P, Han J and Hui L: MAPK signaling in inflammationassociated cancer development. Protein Cell 1:218-226, 2010.

13. Zhou J, Liu M, Aneja R, Chandra R, Lage H and Joshi HC: Reversal of P-glycoprotein-mediated multidrug resistance in cancer cells by the c-Jun NH2-terminal kinase. Cancer Res 66: 445-452, 2006

14. Han L, Wang Y, Guo X, Zhou Y, Zhang J, Wang N, Jiang J, Ma F and Wang Q: Downregulation of MDR1 gene by cepharanthine hydrochloride is related to the activation of c-Jun/JNK in K562/ADR cells. Biomed Res Int 2014: 164391, 2014.

15. Aldonza MB, Hong JY, Bae SY, Song J, Kim WK, Oh J, Shin Y, Lee SH and Lee SK: Suppression of MAPK signaling and reversal of mTOR-dependent MDR1-associated multidrug resistance by 21alpha-methylmelianodiol in lung cancer cells. PLoS One 10: e0127841, 2015.

16. Marozin S, Altomonte J, Apfel S, Dinh PX, De Toni EN, Rizzani A, Nüssler A, Kato N, Schmid RM, Pattnaik AK, et al: Posttranslational modification of vesicular stomatitis virus glycoprotein, but not JNK inhibition, is the antiviral mechanism of SP600125. J Virol 86: 4844-4855, 2012.

17. Sun J, Yeung CA, Co NN, Tsang TY, Yau E, Luo K, Wu P, Wa JC, Fung KP, Kwok TT, et al: Clitocine reversal of P-glycoprotein associated multi-drug resistance through downregulation of transcription factor NF-kappaB in R-HepG2 cell line. PLoS One 7: e40720, 2012.

18. Kanagasabai R, Krishnamurthy K, Druhan LJ and Ilangovan G: Forced expression of heat shock protein 27 (Hsp27) reverses P-glycoprotein (ABCB1)-mediated drug efflux and MDR1 gene expression in adriamycin-resistant human breast cancer cells. J Biol Chem 286: 33289-33300, 2011. 